\title{
Pathological reacting to meteorological changes as a risk-factor of cardio-vascular pathology in the north
}

\author{
Evgeniya Sevostyanova*, Vyacheslav Hasnulin \\ State Scientific Center of Clinical and Experimental Medicine SB RAMS, Novosibirsk, Russia \\ E-mail address: \\ luck.nsk@rambler.ru(E. Sevostyanova)
}

\section{To cite this article:}

Evgeniya Sevostyanova, Vyacheslav Hasnulin. Pathological Reacting to Meteorological Changes as a Risk-Factor of Cardio-Vascular Pathology in the North. Clinical Medicine Research. Vol. 2, No. 4, 2013, pp. 53-57. doi: 10.11648/j.cmr.20130204.13

\begin{abstract}
Background Cardio-vascular pathology is widespread in the North. It is more severe and hard than in moderate latitudes. There are little data available describing reactions of cardio-vascular system to changes of climatic, meteorological and helio-geophysical factors and their role in the development of the disease. The purpose of our study was to study the role of pathological reacting to climate and meteorological changes in development of cardio-vascular pathology in the North. Methods Clinical and physiological material of 1720 persons including 980 patients with cardiovascular pathology (arterial hypertension I, II and coronary artery disease, stable angina pectoris) was studied. The complex of clinico-physiological, electrocardiographic and computer-analytical methods, including the original computer program "Screenmed” (registration by RosPatent №970035 from 29.01.1997) was used. The program includes a questionnaire for obtaining information about reacting of an organism to changes of climate, meteorological and helio-geophysical factors. The information of climate-meteorological and helio-geophysical factors was obtained from geophysical stations. Results The study indicates that most of patients with cardio-vascular pathology have high level of pathological meteosensitivity. The patients with arterial hypertension associated with coronary artery disease are most meteosensitive. A degree of pathological reacting to meteorological and geophysical factors determines an increase in complaints, clinical signs of a disease and electrocardiographic changes. Conclusion The study revealed significant association between pathological reacting to meteorological and helio-geophysical changes and the level of cardio-vascular disturbances. It has been found that pathological reacting of human organism to changes of climatic, helio-geophysical, meteorological and other biospheric factors of the environment is an important link in pathogenic mechanism of cardio-vascular pathology in the extreme conditions of the North.
\end{abstract}

Keywords: Cardio-Vascular Pathology, Meteopathic Reactions, Sensitivity to Weather, North

\section{Introduction}

Numerous studies have showed the high prevalence of cardio-vascular pathology in the North $[1 ; 2]$. Cardiovascular events in high latitudes are more severe and hard than in middle latitudes. At the same time, preventive and medical methods, based on traditional approaches, are often appeared to be not sufficiently effective. This is proved by the considerable increase in morbidity and mortality from cardio-vascular diseases in different regions of the North [3].

A more perspective approach to solve the problem is an ecological one. According to this, disturbances in adaptation to natural factors of the environment lay in the basis of cardio-vascular pathology in extreme environmental conditions $[3 ; 4 ; 5 ; 6]$. Manifested reactions of cardio-vascular system on changes of climate, heliogeophysical, seasonal, meteorological and other biosphere factors have been described $[7 ; 8 ; 9 ; 10 ; 11 ; 12$; 13]. The data of literature and our previous researches allowed us to set up such concepts as physiological and pathological meteosensitivity [14]. By the term "physiological" meteosensitivity we mean the complex of normal physiological reactions of an organism to changes of climate, meteorological and helio-geophysical factors of the environment, providing health of the organism. "Pathological" meteosensitivity is the reaction of an organism to perturbations of meteorological and heliogeophysical factors by development of disadaptive and pathological changes, which are manifested by worsening of the subjective state of an organism and numerous functional disorders.

The purpose of investigation: to study the role of 
pathological meteosensitivity in development of cardiovascular pathology in the North.

\section{Materials and Methods}

The present work contains clinical and physiological material of 1720 persons: 825 men and 895 women. The main group included 980 patients with cardio-vascular pathology - all inhabitants of northern region of Russian Federation. The patients were admitted to the specialized (cardiological) department of our hospital. There were 375 patients with essential hypertension I (according to classification of the World Health Organization), 225 patients with essential hypertension II (according to classification of the World Health Organization); 140 patients with coronary artery disease, stable angina pectoris, functional classes 2 and 3, (according to Canadian Cardiovascular Society [15] ) and 240 patients with coronary artery disease, stable angina pectoris, functional classes 2 and 3 (according to Canadian Cardiovascular Society) associated with hypertension II. The average age was 37,5 $\pm 0,6$ (range-25-60 years). Verification of coronary artery disease and essential hypertension was based on the World Health Organization criteria. It was of based on standard research outcomes, including collection of anamnesis, careful clinical investigation, electrocardiography, veloergometry and echocardiography of heart, aorta and its branches. Control groups included 415 practically healthy persons- inhabitants of Far North and 325 practically healthy persons - inhabitants of moderate latitudes, with the average age - 37,8 $\pm 0,5$ (range25-60 years).

All patients gave the written informed consent prior to the investigation. The study conforms to the principles outlined in the 1975 Declaration of Helsinki.

Estimation of pathological meteosensitivity level and main complications and clinical signs of a disease was carried out with the use of original computer program "SCREENMED" (registration by RosPatent №970035 from 29.01.1997) [14]. The program includes a questionnaire for obtaining information about main functional and pathological disorders of an organism. The level of pathological meteosensitivity was estimated as a sum of subjective reactions to changes of meteogeophysical factors.

All patients were subjected to standard electrocardiography (ECG) in 12 assignments.

The information of climate-meteorological and geophysical situation (gravitational fluctuations, magnetic storms, geomagnetic $\mathrm{K}$-indices, daily atmospheric pressure, temperature and humidity) was obtained from geophysical stations.

Statistical treatment of the data was carried out with the use of applied programs Statistica-6. For comparison between groups, Student's t-test was used. Average values were presented as mean \pm S.E. Differences were considered significant when a p-value was smaller than 0,05 . Correlation analysis was also used.

\section{Results}

It was found, that $24,5 \%$ ( 240 persons) of the patients with cardio-vascular pathology had low, 21,4\% (210 persons) - average and 54,1\% (530 patients) -high level of pathological meteosensitivity. As shown in Table 1, mean values of pathological meteosensitivity in the patients with cardio-vascular diseases were higher in comparison to the control group $(\mathrm{p}<0,001)$. The mean value of pathological meteosensitivity in the patients with arterial hypertension II, associated with coronary artery disease was much higher than in the patients with essential hypertension I $(p<0,001)$.

Table 1. Levels of pathological meteosensitivity in patients with chronic cardio-vascular diseases

\begin{tabular}{|c|c|c|c|c|c|c|}
\hline Index & $\begin{array}{c}\text { Patients with AH } \\
1 \mathrm{n}=375\end{array}$ & $\begin{array}{c}\text { Patients with AH } 2 \\
n=225\end{array}$ & $\begin{array}{c}\text { Patients with CAD } \\
\quad \mathbf{n}=\mathbf{1 4 0}\end{array}$ & $\begin{array}{c}\text { Patients with } \\
\text { AH, CAD } \\
\text { n=240 }\end{array}$ & $\begin{array}{c}\begin{array}{c}\text { Healthy persons } \\
\text { of moderate latitudes } \\
n=325\end{array} \\
\end{array}$ & 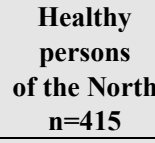 \\
\hline & 1 & 2 & 3 & 4 & 5 & 6 \\
\hline $\begin{array}{c}\text { Level of pathological } \\
\text { meteosensi-tivity, } \\
\text { units }\end{array}$ & $2,4 \pm 0,3 *$ & $3,8 \pm 0,4^{*}$ & $3,2 \pm 0,4 *$ & $4,7 \pm 0,4^{*}$ & $0,3 \pm 0,1$ & $0,4 \pm 0,1$ \\
\hline
\end{tabular}

Footnotes: $\mathrm{AH}$ - arterial hypertension; $\mathrm{CAD}$ - coronary artery disease significance of differences between 1 и 2 groups $<0,05$, between 1 и 4 groups $p<0,001$, between 3 и 4 groups $p<0,01$; * significance of differences with control groups ( 5 и 6 ) $p<0,001$

Comparative correlation analysis revealed significant positive associations between pathological meteosensitivity and arterial hypertension $(\mathrm{r}=0,79, \mathrm{p}<0,05)$; pathological meteosensitivity and incidences of angina pectoris $(r=0,56$, $\mathrm{p}<0,05)$.

The method of shares comparison (Table 2) showed that percentage of patients with high pathological meteosensitivity was considerably $(p<0,001)$ larger in the patients with arterial hypertension II $(57,8 \%)$ and especially in the patients with arterial hypertension II associated with coronary artery disease $(79,2 \%)$ as compared to the patients with arterial hypertension I (36\%). Most serious clinical signs and symptoms of cardio-vascular pathology are presented in Table 3. A rise of pathological meteosensitivity was accompanied by an increase in the number of complaints and main clinical symptoms: 
incidence of angina, cartilages, various cordial rhythm violations and headaches, connected with increased blood

pressure.

Table 2. Percentage of patients with different levels of pathological meteosensitivity in different nosological groups (\%)

\begin{tabular}{llll}
\hline Group & $\begin{array}{l}\text { Percentage of patients with } \\
\text { low meteosensitivity }\end{array}$ & $\begin{array}{l}\text { Percentage of patients with } \\
\text { average meteosensistivity }\end{array}$ & $\begin{array}{l}\text { Percentage of patients with } \\
\text { high meteosensitivity }\end{array}$ \\
\hline Patients with AH 1 $\mathrm{n}=375$ & 41,3 & 22,7 & 36 \\
Patients with AH 2 n=225 & $15,5^{* * *}$ & 26,7 & $57,8^{*}$ \\
Patients with CAD n=140 & 21,4 & 25 & 53,6 \\
Patients with AH2 and CAD n=240 & $8,3^{* * *}$ & 12,5 & $79,2^{* * *}$ \\
\hline
\end{tabular}

Footnotes: AH1 - arterial hypertension 1; AH2 - arterial hypertension 2; CAD - coronary artery disease; significance of differences with the group of patients with $\mathrm{AH} 1 * \mathrm{p}<0,05, * * \mathrm{p}<0,001$

Table 3. Clinical signs of a disease in cardiological patients with different levels of pathological meteosensitivity (\%)

\begin{tabular}{llll}
\hline Index & $\begin{array}{l}\text { Patients with } \\
\text { low meteosensitivity } \\
\mathbf{n = 2 4 0}\end{array}$ & $\begin{array}{l}\text { Patients with } \\
\text { average meteosensitivity } \\
\mathbf{n = 2 1 0}\end{array}$ & $\begin{array}{l}\text { Patients with } \\
\text { high meteosensitivity } \\
\mathbf{n = 5 3 0}\end{array}$ \\
\hline Pains in chest & 1 & 2 & 3 \\
Incidence of angina & 22,9 & 52,4 & $52,8^{*}$ \\
Cardialgia & 16,7 & $31^{*}$ & 48,1 \\
Frequent headaches & 6,3 & $33,3 *$ & 33,0 \\
Arrhythmia & 14,6 & 42,9 & $50,9^{*}$ \\
Tachycardia & 14,6 & $42,9^{*}$ & $43,4^{*}$ \\
Weakness & 35,4 & 61,9 & $73,6^{*}$ \\
\hline
\end{tabular}

Footnotes: * - significance of differences $p<0,05$ with the group 1

Table 3 shows that a degree of pathological meteoreacting to changes of meteorological and geophysical factors in patients with cardio-vascular diseases determines an increase in complaints and clinical symptoms of a disease. Pain in the chest was registered 4 times more often in the patients with high degree of pathological meteosensitivity $(52,8 \%)$ than in the patients with low meteosensitivity $22,9 \%(p<0,05)$. The pains in the chest were located in its left part, behind the breastbone, in pericardial area. They had a pressing, pricking or compressing character and occurred while resting and on exertion. They had various duration, often appeared when the weather was changing and also at psychoemotional stress. Frequent chest pains in the patients with high meteosensitivity are likely to show deepening cardiovascular disfunction with an increase in pathological reacting on geophysical and meteorological fluctuations. There were significant differences in frequency of tachycardia, arrhythmia, headaches and weakening between the patients with high meteosensitivity and the patients with low meteosensitivity.

To analyze electrical function of the heart depending on pathological meteosensitivity we studied the basic indices of electrocardiography. There was registered lengthening of time electrocardiography characteristics (P-wave, QRScomplex) at an increase in pathological meteosensitivity (Table 4). We observed a high frequency of conductivity impairment in the meteosensitive patients (Table 5).

Table 4. Electrocardiography indices in the patients with cardio-vascular pathology in the North in dependence on the level of pathological meteosensitivity

\begin{tabular}{lllll}
\hline Index & $\begin{array}{l}\text { Patients with low } \\
\text { meteosensitivity } \mathbf{n = 2 4 0}\end{array}$ & $\begin{array}{l}\text { Patients with average } \\
\text { meteosensitivity } \mathbf{n = 2 1 0}\end{array}$ & $\begin{array}{l}\text { Patients with high } \\
\text { meteosensitivity } \mathbf{n}=\mathbf{5 3 0}\end{array}$ & P value \\
\hline Heart rate & $63,9 \pm 0,9$ & $62,5 \pm 1,4$ & $63,8 \pm 2,7$ & $1-2,1-3-\mathrm{p}<0,05$ \\
$\mathrm{P}, \mathrm{s}$ & $0,10 \pm 0,004$ & $0,11 \pm 0,001$ & $0,11 \pm 0,002$ & \\
$\mathrm{PQ}, \mathrm{s}$ & $0,16 \pm 0,006$ & $0,16 \pm 0,003$ & $0,17 \pm 0,004$ & $1-2,1-3-\mathrm{p}<0,001$ \\
QRS, s & $0,09 \pm 0,001$ & $0,10 \pm 0,001$ & $0,10 \pm 0,002$ & $0,40 \pm 0,008$ \\
$\mathrm{QT}, \mathrm{s}$ & $0,38 \pm 0,007$ & $0,39 \pm 0,009$ & & \\
\hline
\end{tabular}

Table 5. Electrocardiography indices in patients with different levels of pathological meteosensitivity (\%)

\begin{tabular}{|c|c|c|c|}
\hline Index & $\begin{array}{l}\text { Patients with low meteosensitivity } \\
\mathrm{n}=\mathbf{2 4 0}\end{array}$ & $\begin{array}{l}\text { Patients with average meteosensitivity } \\
\mathrm{n}=\mathbf{2 1 0}\end{array}$ & $\begin{array}{l}\text { yatients with high } \\
\text { meteosensitivity } \mathbf{n}=\mathbf{5 3 0}\end{array}$ \\
\hline Bradycardia & 28,4 & 28,6 & 30,3 \\
\hline Slowing of conductivity & $24,3 *$ & 30,5 & $50,8^{*}$ \\
\hline Amplified or inverted T-wave & $20,7^{*}$ & 32,2 & $39,5^{*}$ \\
\hline High-amplitude T & 24,5 & 28,6 & 31,6 \\
\hline Signs of left ventricular hypertrophy & $26,6 * *$ & 34,5 & $52,6 * *$ \\
\hline
\end{tabular}

Footnotes: * significance of differences $\mathrm{p}<0,05$ between $1-3$ groups 
Conductivity appeared to be dependent on a degree of pathological meteosensitivity. The analysis of the indices presented in Table 5 showed that the share of persons with conductivity impairment (slowing of auricle and ventricular conductivity) was significantly $(p<0,01)$ higher in the patients with high meteosensitivity $(50,8 \%)$ than in the patients with low meteosensitivity $(24,3 \%)$. The worsening of conductivity function may indicate to deepening myocardial damage due to frequent pathological meteoreacting. At a morphological level it may be the consequence of sclerosis processes development in myocardium.

Analysis of a final part of ventricular complex in the meteosensitive patients revealed the high frequency of changes in T-wave size: both decrease in its amplitude and inversion and considerable increase in amplitude. The revealed changes may be connected both with worsening of coronary circulation and with changes in metabolic processes in myocardium, occurring due to frequent pathological reacting to meteo-geophysical perturbations.

Further analysis of electrocardiography showed high frequency of signs, indicating to left ventricular hypertrophy. There was disclosed a tendency to a more frequent development of left ventricular hypertrophy in the patients with manifested meteopathic reactions as compared to the patients with low meteosensitivity. The data point to more intensive heart work in the highly meteosensitive patients, an increase in the loads on left ventricular, probably due to frequent rises of arterial pressure and progress of arterial hypertension. Electrocardiographic (ECG) findings showed more frequent heart rate, single and group extrasystoles, magnification of $\mathrm{P}$ - and T-waves during geophysical perturbations. The significant $(p<0,001)$ left deviation of QRS vector in the frontal axis was revealed during magnetic storms. It indicates, that the strong influence of the planetary electromagnetic field directed almost perpendicularly to the Earth's surface in high latitudes resulted in a displacement of the heart axes into horizontal position. We found that a value of an ascending part of GRS-complex in a depolarization phase of V2 and V5 assignments of ECG increased more than on $7-10 \%$ during a quick amplification of geomagnetic field induction as compared to the periods of calm geomagnetic situation. These data are the evidence of an increased heart activity during magnetic storms.

\section{Discussion}

The significance of the study is that it makes it possible to understand new mechanisms of cardio-vascular pathology development in the people living in extreme climate-geophysical conditions of the North. It appears that in the case of exhausted adaptive reserves meteo- geophysical perturbations cause inadequate pathophysiological reactions. This phenomenon is known as a pathological meteosensitivity. We have revealed the role of pathological meteosensitivity in development of cardio-vascular pathology.

Our findings have demonstrated the high level of pathological meteo-reacting in patients with cardiovascular pathology in the North, which is significantly higher as compared to healthy persons (inhabitants of the North and moderate latitudes). Seriousness of clinical signs in patients with arterial hypertension and coronary artery disease appears to be associated with pathological meteosensitivity.

We have showed that the level of pathological meteosensitivity in cardiological patients of the North depends on functional and organic state of cardio-vascular system, nozology and a stage of a disease. The obtained results point out to the association between cardio-vascular pathology and the level of pathological reacting to changing climate, meteorological, geophysical and cosmic factors of the environment. It may be explained by the progressive worsening of adaptive abilities at an increase in functional and organic disturbances of cardio-vascular system. Our data have showed that meteopathic reactions of cardio-vascular system are the serious ones, often manifesting themselves in the form of hypertensive crises, incidences of angina pectoris and cardialgies. Moreover they often help to develop severe complications: myocardial infarctions and cerebral thromboses. At the same time, our study, which has revealed high prevalence of pathological meteosensitivity in persons with the functional and pathological disturbances of cardio-vascular system, proves that meteopathic reactions are not only manifestations of disadaptation or acutness of a disease but to a large extent they appear to be an important pathogenetic mechanism of formation and development of cardio-vascular diseases in unfavorable regions (as far as the climatic and geophysical conditions are concerned).

The significant dependence of cardio-vascular system function on geomagnetic perturbations has allowed us to assume that one of the most important mechanism of development of cardio-vascular pathology in the North is a mechanism of pathological reacting on modifications of the Earth's electromagnetic field. It is based on the dependence of internal electromagnetic fields (most importantly - the heart pulsating electromagnetic field) on modification of value and direction of external electromagnetic field. Considering the pulsating electromagnetic field generated by the heart in electromagnetic field of the Earth and according to the laws of physics we can state that considerable increase in induction of electromagnetic field of the Earth in periods of magnetic storms causes an increase in tension of electromagnetic field of a person connected first of all with the heart action potential. Thus, 
we believe that one of the important mechanisms of pathological meteosensitivity is disturbance of electrical activity of the heart.

Summarizing the results of the study we may conclude that one of the main risk factors in the development of cardiovascular pathology, especially in extreme environmental conditions, is the lack of coordination of vital activity with changes in cosmic, climate, geophysical, meteorological and other biospheric characteristics of the environment. Better understanding of these data would assist clinicians in treatment and prevention of cardiovascular diseases and their serious complications.

\section{References}

[1] Grundy S.M., Wilhelmsen L., Rose G., Campbell R.W.F., Assman G. Coronary heart disease in high-risk populations: Lessons from Finland. Europ. Heart J. 1990; 11: 469-471.

[2] Peters R.W., Brooks M.M., Zoble R.G., Liebson P.R., Seals A.A. Chronobiology of acute myocardial infarction: Cardiac arrhythmia suppression trial experience. The American Journal of Cardiology 1996; 78: 1198-1201.

[3] Hasnulin V.I., Hasnulina A.V., Sevostyanova E.V. Northern cardiometeopathies. Novosibirsk: Creative Union "SouthWest", 2004.

[4] Kaznacheev V.P. Modern problems of adaptation. Novosibirsk: Science, 1980.

[5] Avcyn A.P. Introduction in geographic pathology. Moscow: Medicine, 1972.

[6] Driscoll D.M. A perspektive on weather - human response relationship. Int. J. Envioron. Stud.1990; 36:19.

[7] Thompson D. R., Pohl J. E., Tse Y.Y. S., Hiorns R.W. Meteorological factors and the time of onset of chest pain in acute myocardial infarction. Int. J. Biometeorol. 1996; 39: $116-120$.

[8] Donaldson G.C., Ribinson D., Allaway S. Z. An analysis of arterial disease mortality and BUPA health screening data in relation to outdoor temperature. Clin.Sci. 1997; 3: 261 - 268.

[9] Postolache T., Gautier S., Laloux Br., Safar M., Benetos A. Possitive correlation between the blood pressure and heart rate response to the cold pressor test and the environmental temperature in older hypertensives. Amer. J. Hypertension 1993; 6: 376 - 381 .

[10] Grigoryev I.I. The weather and the health. Moscow: Avicenna, 1996.

[11] Stoupel E., Abramson E., Sulkes J., et al. Relationship between suicide and myocardial infarction with regard to changing physical environmental conditions. Int. J. Biometeorol. 1995; 38: 199- 203.

[12] Goerrea S., Eglib C., Gerberc S., et al. Impact of weather and climate on the incidence of acute coronary syndromes. International Journal of Cardiology 2007; 118: 36-40.

[13] Lapko A.V., Policarpov L.S. Climate and Health. Meteotropic reactions of cardio-vascular system. Novosibirsk, 1994:104.

[14] Hasnulin V.I., Nadtochiy L.A., Hasnulina A.V. Principles of medical selection in high latitude migration. Novosibirsk, 1995.

[15] Campeau L. Grading of angina pectoris. Circulation 1976; 54: 522-523. 